\title{
Virginia Woolf e o sentido do tempo
}

\author{
Virginia Woolf and a sense of time
}

Rossana Pinheiro-Jones

Doutor em História Professor da Universidade Federal de São Paulo rossana.unifesp@gmail.com

Resumo: Neste artigo, apresentamos reflexões sobre a importância que Virginia Woolf atribuiu à História e sua escrita, a partir de uma investigação sobre o sentido do tempo em um de seus primeiros contos, $O s$ diários da Senhora Joana Martyn. Escrito em 1906, nele, uma historiadora renomada encontra o manuscrito de um diário escrito em 1480 por uma jovem da família Martyn, de Norfolk. Ao ser comparado com textos posteriores, sobretudo aqueles considerados autobiográficos, este conto lança luz sobre o conhecimento, interação e posicionamento de Virginia acerca de debates historiográficos de sua época, dentre os quais os limites e possibilidades da relação entre Literatura e História.

Palavras-chave: Virginia Woolf, Literatura, História, escrita da história, Idade Média

\begin{abstract}
This article aims to explore the importance Virginia Woolf assigned to History and its writing. Our assumptions are based on an inquiry about the sense of time in one of Woolf's first short story, entitled The Journal of mistress Joan Martyn. In this short story conceived in 1906, a prestigious female historian comes across the manuscript of a journal written in 1480 by a young woman, a member of the Martyn family from Norfolk. When compared with some of Woolf's later works, especially her autobiographical writings, this short story highlights the writer's knowledge about some of the most important historiography debates of her times, amongst which the limitations and possibilities of the relationship between Literature and History.
\end{abstract}

Keywords: Virginia Woolf, Literature, History, the writing of history, Medieval Ages. 
É uma época estéril e exausta, repetimos; devemos olhar para o passado com inveja [...]. Nenhuma outra geração precisou enaltecer seus contemporâneos mais do que a nossa. Estamos brutalmente descolados de nossos predecessores. Uma mudança na balança - a guerra, o repentino deslize das massas mantidas em posição por séculos - sacudiu a fábrica de alto a baixo, nos alienando do passado e fazendo de nós, talvez, muito vivamente conscientes do presente. Todos os dias, nos pegamos fazendo, dizendo, ou pensando coisas que teriam sido impossíveis para nossos pais. E sentimos as diferenças que não haviam sido notadas [...]. Nenhuma época poderia ter sido tão rica como a nossa em escritores determinados a dar expressão às diferenças que os separam do passado e não às semelhanças que os conectam a ele.

Virginia Woolf. Como se ataca um contemporâneo (1923: 26-27).

\section{Virginia Woof, pensadora do tempo?}

Virginia Woolf (1882-1941) é amplamente conhecida e aclamada como uma das principais escritoras de língua inglesa do século XX. Não apenas sua obra fala por si e demonstra a capacidade linguística e estilística que fez sua fama, como sua vida agitada e controversa talvez tenha contribuído para fazer sua notoriedade ainda maior. Londrina por nascimento, membro de uma família que integrava uma elite intelectual composta por homens de leis, letras e artes ${ }^{1}$, a tragédia marcou sua trajetória desde seus primeiros anos quando, recordaria mais tarde, fora tocada de maneira imprópria pelos meio-irmãos em um dia de verão na idílica St. Ives ${ }^{2}$, e no quarto que passara a ocupar nos últimos andares da sombria casa de Hyde Park Gate ${ }^{3}$. Em 1895, perderia sua mãe, a mulher que, conforme

\footnotetext{
1 "Who was I then? Adeline Virginia Stephen, the second daughter of Leslie and Julia Prinsep Stephen, born on $25^{\text {th }}$ January 1882 , descended from a great many people, some famous, others obscure; born into a large connection, born not of rich parents, but of well-to-do parents, born into a very communicative, literate, letter writing, visiting, articulate, late nineteenth century world". WOOLF, Virginia. "A sketch of the past" (1939-1941). In: Moments of Being. Virginia Woolf: the complete collection. Golden Deer Classics. Versão kindle, posição 126910. Neste artigo, as obras de Virginia Woolf são citadas a partir desta versão a menos que se ateste o contrário. A respeito da descendência erudita e privilegiada de Woolf, ver também WILLIAMS, 2011: 201-230; BELL,1972.

2 "Once when I was very small Gerald Duckworth lifted me onto this, and as I sat there he began to explore my body. I can remember the fell of his hand going under my clothes; going firmly and steadily lower and lower. I remember how I hoped that he would stop; how I stiffened and wriggled as his hand approached my private parts. But it did not stop. His hand explored my private parts too" (WOOLF, 1939-1941: posição 126969).

3 "It was long past midnight that I got into bed and sat reading a page or two of Marius the Epicurean for which I had then a passion. There would be a tap at the door; the light would be turned out and George would fling himself on my bed, cuddling and kissing and otherwise embracing me in order, as he told $\mathrm{Dr}$
} 
reelaboraria em 1927 na obra Rumo ao Farol ${ }^{4}$, era a totalidade da existência, da vida doméstica e familiar, o "anjo na casa", sua primeira memória. Stella, sua meia-irmã e filha mais velha de Júlia Prinsep Stephen, assumiria o encargo da casa após a morte da mãe, mas também faleceria dois anos depois, grávida e recém-casada. Antes de completar 20 anos, Virginia enfrentaria ainda a morte do pai, a do irmão mais velho, Thoby, e experimentaria crises de depressão e ansiedade. Em 1941, também de forma trágica, encerraria sua vida, mergulhando no rio Ouse com pedras nos bolsos, quando não mais suportava ouvir o barulho dos aviões alemães que sobrevoavam sua casa em Sussex ou bombardeavam suas residências londrinas, em Tavistock Square e Mecklenburgh Square, fornecendo indícios de uma invasão iminente e deixando vidas em ruínas ${ }^{5}$; ou por temer o retorno das vozes que anunciavam a possibilidade de novo mergulho na loucura, tal qual declararia na famosa nota deixada ao seu marido, Leonard, antes de partir ${ }^{6}$.

Mas não só de tragédia foi feita sua fama. $\mathrm{O}$ escândalo e a polêmica também estiveram presentes e foram a marca de um grupo que passou a se reunir no número 46 de Gordon Square, Londres, casa para onde os irmãos Stephen se mudaram após a morte do pai em 1904. O grupo de Bloomsbury, como ficou conhecido, era composto por homens e mulheres que se reuniam às quintas à noite para discutir e produzir arte em um clima de liberdade e contestação ou recusa à sociedade que os precedera, austera em traços e cores (SPALDING, 2016) e em repressão sexual. Em memórias escritas entre

Savage later, to comfort me for the fatal illness of my father - who was dying three or four storeys lower down of cancer”. WOOLF, Virginia. “Old Bloomsbury”. In: op cit, posição 128702.

4 "Until I was in the forties - I could settle the date by seeing when I wrote To the lighthouse, but am too casual here to bother to do it - the presence of my mother obsessed me. I could hear her voice, see her, imagine what she would do or say as I went about my day's doings. She was one of the invisible presences who after all play so important a part in every life" (WOOLF, 1939-1941: posição 127159).

5 "June 8th 1940. I have just found this sheaf of notes, thrown away into my waste-paper basket. I had been tidying up; and had cast all my life of Roger into that large basket, and with it, these sheets too. Now I am correcting the final page proofs of Roger; and it was to refresh myself from that antlike meticulous labour that I determined to look for these pages. Shall I ever finish these notes - let alone make a book from them? The battle is at its crisis; every night the Germans fly over England; it comes closer to this house daily. If we are beaten then - however we solve that problem, and one solution is apparently suicide (so it was decided three nights ago in London among us) book writing becomes doubtful". Ibid, posição 127487. Também as entradas de 18 de setembro, 17 de outubro e 20 de outubro de 1940 de seu Diário retratam a devastação de suas casas durante o bombardeio de Londres: "Wednesday, 18 September: 'We have need of all our courage' are the words that come to the surface this morning; on hearing that all our windows are broken, ceilings down, \& most of our china smashed at Meck. Sq. The bomb exploded. Why did we ever leave Tavistock? - whats the good of thinking that? We were about to start for London, when we got on to Miss Perkins who told us. The Press - what remains - is to be moved to Letchworth. A grim morning. How can one settle into Michelet \& Coleridge? As I say, we have need of courage. A very bad raid last night on London"; "Thursday, 17 October: Our private luck has turned. John says Tavistock Sqre is no more" (WOOLF, 1940: posição 153812; 153930).

6 "I feel certain I am going mad again: I feel we can't go through another of those terrible times ... You have given me the greatest possible happiness ..." (apud LEE, 2008: 30). 
1920 e 1921, intituladas Velho Bloomsbury, Virginia apresentaria um grupo cortado em dois momentos distintos a partir do casamento da irmã Vanessa com o crítico de arte Clive Bell, em 1907, após a morte de Thoby. Entre 1904 e 1907, Gordon Square seria frequentada pelos colegas extraordinários de Thoby, todos formados em Cambridge: Sydney-Turner era considerado um prodígio de aprendizado e grande conhecedor de literatura grega; Lytton Strachey foi apresentado como a própria essência da cultura e um tanto excêntrico, já que ouvinte da música das esferas; Clive Bell, seria um misto de Keats e homem de campo, pelo interesse que possuía por poesia e a arte da caça; Leonard Woolf, um judeu misantropo que havia desistido da civilização e partira rumo aos trópicos. O caráter de novidade, próprio aos tempos modernos (SPIROULOU, 2010; MALCOLM, 2010), que emanava do grupo torna-se evidente quando tais encontros são comparados com as reuniões presididas pela família até o falecimento de Sir Leslie Stephen.

Em Hyde Park Gate, o dia transcorria sob os mandamentos de uma sociedade patriarcal vitoriana de classe média alta, reunida em torno da mesa de chá, da divisão dos horários, dos espaços e dos gêneros. Segundo Woolf recordaria em Um esboço do passado, a pressão da sociedade vitoriana aumentaria por volta de 16h30, quando ela e Vanessa deveriam estar em casa para receber mulheres e, sobretudo, homens ilustres e eruditos. Caberia e elas manter uma conversa leve, casual, em tom de fofoca e entretenimento, enquanto passavam o creme ou o açúcar. A vida do intelecto, da investigação, de assuntos relevantes como política, economia e legislação, estava reservada aos homens, principalmente a seu pai, quando este, longe dos olhos públicos, se fechava em seu escritório para preparar as edições do Dicionário de Biografia Nacional, que faria dele um respeitado intelectual, não só entre seus pares, como para a posteridade. Neste mundo vitoriano, Virginia, entretanto:

Sentia-me como um cigano ou uma criança se sente, que se coloca na ponta de uma tenda e vê o circo acontecendo no interior. Eu estava em pé na sala de estar de Hyde Park Gate e via a sociedade a todo vapor. Via George como um acrobata pulando por entre de argolas. Via-o às vezes com medo, às vezes com admiração. A sociedade patriarcal da época vitoriana estava a todo vapor na nossa sala de estar. Ela tinha, claro, muitas partes. Vanessa e eu não éramos chamadas a tomar parte em alguns dos atos. Éramos apenas chamadas a admirar e aplaudir quando nossos parentes masculinos caminhavam entre diferentes figuras do jogo intelectual. (WOOLF, 1939-1941: 128346-128352). 
Em Gordon Square, em contrapartida, as reuniões aconteciam tarde da noite, longe das mesas de chá, em cômodos esfumaçados que comportavam brioches, café e whisky. A casa, que adquiriu nova tapeçaria e decoração adequada aos novos tempos, acolheria homens que nem sempre falavam, mas ouviam o que Virginia e Vanessa tinham a dizer sobre o estatuto do belo, do bem e da realidade. Tais conversas abstratas regadas a meticulosas demonstrações e defesas de argumentos seriam a marca do Velho Bloomsbury e teria seu fim quando casamento e amor adentraram as portas de Gordon Square, marcando uma nova fase para o grupo de amigos, com a adesão de novos membros e, sobretudo, pela mudança de direção no que Virginia consideraria a ida do geral para o particular e o início da crítica, da distinção e da comparação. E, mais do que isso, a partir de 1907, questões mais viscerais como sexo e homossexualidade entrariam para a pauta. Se antes as convenções sociais demandavam que mesmo entre irmãos não se falasse sobre práticas sexuais, menstruação e envolvimentos amorosos, não é de se estranhar que a chegada de Clive Bell, Sydney-Turner, Roger Fry, Duncan Grant e Lytton Strachey com a partilha de suas aventuras homossexuais tenha tornado memorável a seguinte passagem, relatada por Woolf nestas memórias:

Era uma noite de primavera, Vanessa e eu estávamos sentadas na sala de estar. A sala de estar havia mudado consideravelmente seu caráter desde 1904. A era Sargent-Furse havia terminado. A época Augustus John estava despontando. Seu Píramo ocupava uma parede inteira. Os retratos de meu pai e minha mãe, pintados por Watts, estavam pendurados no andar de baixo, se é que o estavam realmente. Clive havia escondido todas as caixas de fósforos porque seu azul e o amarelo brigavam com a cor predominante da decoração. Em algum momento, Clive poderia entrar e ele e eu começaríamos a discutir - de maneira amigável e impessoal a princípio; logo estaríamos lançando injúrias um ao outro e andando de um lado para o outro na sala. Vanessa sentava calada e fazia algo misterioso com sua agulha ou tesoura. Eu falava, de maneira egoísta, excitada, sobre mim mesma, sem dúvida. De repente a porta se abriu e a figura comprida e sinistra do Senhor Lytton Strachey apareceu, parada na soleira. Ele apontou com o dedo para uma mancha no vestido branco de Vanessa:

'Esperma?', ele disse.

Pode alguém realmente falar isso? - pensei comigo, e desatamos a rir. Com aquela palavra, todas as barreiras de reserva e reticência caíram. Uma torrente 
do fluido sagrado pareceu nos submergir. O sexo passou a permear nossa conversa. A palavra 'sodomita' nunca estava longe de nossas bocas. Discutíamos sobre a copulação com a mesma animação e abertura com que havíamos discutido a natureza do bem. É estranho pensar como tínhamos sido reticentes e reservados por tanto tempo (WOOLF, 1920-1921: 128906128918).

A abertura sexual e a falta de convencionalidade vitoriana aplicada às relações continuariam a permear o grupo para além da década de 1910. Baseada e dedicada à sua amante Vita Sackville-West, por exemplo, uma das obras clássicas de Woolf (1928), Orlando, apresentaria uma personagem, um "anjo da história, que percorreria temporalidades diferentes sem se restringir a gênero algum e apontando para a possibilidade de que o humano não teria identidade única ainda que existisse algo de estável ao longo do tempo.

Controvérsias e tragédias à parte, o fato é que a vida de Woolf já foi visitada, revisitada, narrada, construída e reconstruída em incontável número de vezes, principalmente após a popularização da sua imagem como autora maníaco-depressiva obcecada com a morte, propagada pela adaptação de As horas de Michael Cunningham para as telas de cinema (LEE, 2008). Da mesma forma, sua obra não deixou de ser lida e analisada a partir de diferentes e variados aspectos, o que comprova a riqueza de sua reflexão e existência. Um dos aspectos talvez menos explorado, e que tem recentemente atraído a atenção de estudiosos, é sua preocupação com o tempo, com a memória, e com a história. Em 2018, por exemplo, o colóquio Woolf e a escrita da história, organizado em Rouen, teve o intuito de dar visibilidade à rica reflexão que Virginia Woolf atribuiu ao passado, à história e à sua relação com o contemporâneo. Outras obras e teses acadêmicas foram publicadas e defendidas ao longo dos anos 2000, algumas das quais abordaram seus trabalhos mais maduros, naquilo que havia de entrecruzamento entre História e Literatura e propostas de enriquecimento da escrita da história (SPIROPOULOU, 2010); de aspectos autobiográficos (NEVES, 2018); ou de como seu mergulho na Idade Média indicava reflexões sobre seu tempo presente (McAVOY, 2016). Ainda que Woolf tenha se colocado ao lado dos modernos ao frequentemente alertar para a ruptura que os anos pós Primeira Guerra Mundial trariam na relação ao passado, principalmente em termos de arte e de escrita, como pode ser visto em seu ensaio Como se ataca um contemporâneo que serve de epígrafe a este artigo, os dois ensaios 
autobiográficos ou memorialísticos acima citados apontam para um sentido de tempo mais complexo em que o presente é permeado por frestas das quais submerge um passado ainda vivo em paredes, em linhas, em hábitos, em genealogias, e em memórias. Em Um esboço do passado, Virginia Woolf defendeu a escrita como ato de memória, de resgaste da completude do ser, de preservação da própria vida e de elaboração sobre o presente. Seria apenas quando um sujeito vivenciava seu presente de forma atenta, com consciência, no que chamou de "momentos do ser", que poderia quebrar a superfície que dava abertura ao passado:

Eu vejo isto - o passado - como uma avenida que ficou para trás; uma longa faixa de cenas, emoções. Ali, ainda ao final da Avenida estão o jardim e o berçário. Ao invés de lembrar aqui uma cena e ali um som, devo acomodar um plugue na parede; e ouvir o passado. Devo me voltar para agosto de 1890. Sinto que uma forte emoção deve deixar o seu traço; e isto é só uma questão de descobrir como podemos nos apegar de novo a ela, de forma que possamos viver nossas vidas desde o início (WOOLF, 1939-1941: 126943).

A própria estrutura deste ensaio é um exemplo disso e demonstra sua defesa de que o presente guardaria as chaves do passado, já que cada novo tópico de memória teria seu início com a apresentação do presente da escritora. Entretanto, este foi um dos últimos textos escritos por Woolf, elaborado como um momento de respiro entre a escrita da biografia de Roger Fry e de seu último romance Entre os atos. Poderíamos, então, considerar que estas reflexões sobre o tempo, a história e a memória seriam fruto de seu amadurecimento intelectual e de sua inserção em tempos difíceis como os que vivia em meio à Segunda Guerra Mundial, que clamavam por vigília e atenção constantes. Entretanto, o que pretendemos explorar neste artigo, ainda que de forma inicial e ensaística, são indícios de que tais diretrizes e percepções sobre o sentido do tempo já haviam se insinuado em seus primeiros escritos e ensaios, em especial, em um de seus primeiros contos, escrito em 1906, anterior, portanto, à Guerra, no qual construiu um documento histórico do século XV, apresentando, ali também, os diários ou memórias de uma mulher vivendo em tempos não tão seguros ou felizes, rodeada por assaltantes, assassinos e incendiários, em um país que enfrentava guerras civis. 


\section{O Diário da Senhora Joana Martyn e uma Inglaterra medieval imaginada}

E os eventos significam muito pouco a menos que saibamos primeiro a quem aconteceram.

Virginia Woolf, Um esboço do passado (1939-1941: 126910).

Em correspondências trocadas com Violet Dickinson em 1905, Virginia Stephen contava sobre seus encontros e conversas com o historiador do direito medieval e catedrático de Cambridge Frederic William Maitland (Carta 224, 1905; Carta 225, 1905), que, àquela época, escrevia a biografia de Leslie Stephen com o auxílio de Virginia. Contava, ainda, sobre seu trabalho de crítica literária para o Times Literary Supplement; e sobre a experiência de lecionar história da Inglaterra para mulheres da classe trabalhadora (Cartas 223, 225, 229 e 230 de 1905) no Colégio Morley, em caráter voluntário e filantrópico, onde permaneceu até 1907 (LEE, 1998: 219). Embora acreditasse que o crescimento da sua atividade filantrópica era correlato ao enfraquecimento de sua popularidade como escritora (Carta 230, 1905); e que se empenhava em uma tarefa pouco atrativa e reconhecida já que "tenho despejado meu sangue vital nos ossos sombrios dos primórdios da história inglesa durante toda a manhã: elas não se importam" (Carta 227, 1905) e não correspondiam ao desejo de Virginia de "fazê-las sentir a carne e o sangue naquelas sombras" (apud LEE, 1999: 219), o gosto pela reflexão e pelo conhecimento da História já estavam presentes, a ponto de Virginia confidenciar à amiga que "aliás, vou escrever história algum desses dias. Eu sempre amei; quiçá eu pudesse encontrar o pedaço que quero" (Carta 227, 1905).

Não parece ser fortuito, portanto, que em 1906, um de seus primeiros contos tenha como protagonista uma historiadora em andanças pela Inglaterra, à caça de manuscritos originais capazes de lançar luz sobre uma história medieval pouco conhecida, ou não oficial. O Diário da Senhora Joana Martyn atesta ainda a riqueza e os limites da relação entre Literatura e História, já que a história recriada pela literatura pode abarcar ou reconstruir espaços de sociabilidade e caminhos metodológicos talvez ainda não alcançados pela historiografia produzida até o início do século XX. O que temos aqui, portanto, não é um historiador que se pergunta sobre a realidade ou verdade do que produz, mas uma escritora que ao se utilizar de pesquisa e do conhecimento que tem sobre o passado, recompõe o cenário histórico, desafiando o historiador a revisitar seus métodos, objetos e concepção sobre o sentido do tempo e causalidade em História. 
O conto está dividido em dois momentos distintos. A parte inicial, escrita em primeira pessoa, traz Miss Rosamond Merridew, uma historiadora de 45 anos, internacional e nacionalmente reconhecida por suas pesquisas sobre o sistema fundiário da Inglaterra medieval e por seu compromisso com a história, o que lhe resultou na troca de um marido, de uma família e da casa onde envelheceria, por meia dúzia de folhas amareladas. Para desenvolver suas pesquisas, Miss Merridew percorre vilarejos e lugares remotos em busca daqueles pergaminhos que poucos conseguem ou tem interesse em ler, e que apontem para a realidade material dos séculos XIII, XIV e XV. Nessas peregrinações por entre fazendas velhas, salões decadentes, por presbitérios e igrejas, Miss Merridew precisa fazer com que sua voz privada não seja abafada por aquela do Estado e seus agentes oficiais que, assim como ela, andam por essas paragens inspecionando as documentações que a historiadora deseja adquirir.

À primeira vista, já chama a atenção a escolha por uma protagonista feminina, desempenhando com desenvoltura e competência um papel até então quase exclusivamente ocupado por homens. Ainda que em 1906 mulheres já pudessem frequentar cursos universitários como os promovidos pelos Colégios de Girton e Newnham em Cambridge; e após a fundação da London School of Economics em 1895, muitas delas estivessem empenhadas em realizar pesquisas sobre a sociedade e às demandas materiais do período medieval, basta analisar, ainda hoje, programas de curso das cadeiras de Teoria da História ou de História Medieval para encontrarmos uma historiografia europeia dos séculos XIX e XX dominada por nomes masculinos. Raramente, antes dos anos 60, conseguimos citar uma historiadora, medievalista ou não, internacionalmente reconhecida, discutida nas disciplinas, quando abordamos a constituição da História como ciência nos séculos XIX e XX. Pensamos no positivismo de Ranke. Discutimos o historicismo de Langlois e Seignobos. Analisamos as inovações que Michelet trouxe à História ao se concentrar no povo, na feiticeira e na personificação da Nação através de sua santa heroína Joana D’Arc. Apresentamos, com orgulho, a revolução historiográfica proposta pelos Annales com Bloch e Fébvre na virada da década de 20 para a de 30 do século $\mathrm{XX}$, que abririam as pesquisas historiográficas para as Ciências Sociais, a Geografia, os ritos e mitos e, com isso, passaram para a história da historiografia como, nos dizeres de Peter Burke, a Revolução Francesa da historiografia. Mas nos calamos sobre os estudos desenvolvidos por Mary Bateson e Beatrice Webb, as quais, no início do século XX, desenvolviam trabalhos sobre história econômica e social, e procuravam garantir um espaço acadêmico para os estudos medievais, centrados na 
pesquisa em arquivo e na análise de registros da corte senhorial (KORE-SCHRÖDER, 2011: 03-04). Ou desconhecemos Eileen Power que se tornaria não só referência sobre estudos medievais na Inglaterra com sua obra $O$ povo medieval, mas ficaria também conhecida pelos encontros realizados em sua casa em Mecklenburgh Square, para um dos quais Virginia Woolf fora convidada no decorrer dos anos 40 (KORE-SCHRÖDER, 2011: 03-04; McAVOY, 2016). Conhecedora ou não daquelas pioneiras nos estudos medievais ingleses no momento de escrita de seu conto $^{7}$, é meritório e inovador que em 1906 Virginia tenha escolhido como protagonista uma mulher, historiadora e medievalista, interessada em investigar a realidade material dos tempos passados, a fim de restituir seu sangue e carne, ou pernas ${ }^{8}$, tal qual era o intuito de Rosamond Merridew, que considerava, dentre seus méritos, o fato de conseguir fazer com que o sistema de posse fundiária dos séculos XIII, XIV e XV fosse apresentado em sua relação com a vida e com a história doméstica ou familiar daqueles tempos:

Tenho considerado que os meandros da posse fundiária não foram sempre os fatos mais importantes nas vidas dos homens e mulheres e crianças; muitas vezes me atrevi a sugerir que as sutilezas que nos encantam tão intensamente eram mais prova da negligência dos nossos ancestrais do que uma prova de sua assombrosa meticulosidade. Pois que homem são, tive a audácia de observar, poderia ter desperdiçado seu tempo complicando suas leis para o benefício de meia dúzia de antiquários que estavam para nascer cinco séculos depois que estivesse no túmulo? (WOOLF, 1906: 158167-158173).

Deixemos de lado, momentaneamente, a observação que alerta para o perigo de considerações teleológicas em História, para nos concentrarmos em outro aspecto interessante que surge neste conto: não só sua protagonista poderia ser vista como

\footnotetext{
${ }^{7}$ Em Um teto todo seu, concebido como palestra para as estudantes de Girton e Newnham em 1929, Virginia Woolf parece apontar para o conhecimento destas historiadoras ao juxtapor o nome de Mary Bateson da seguinte forma: "Então ali estava eu (chamem-me Mary Beton, Mary Seton, Mary Carmichael ou qualquer outro nome que lhes agrade - pouco importa) [...]". WOOLF, Virginia. Um teto todo seu. Tordesilhas, 2014, p. 13. Também em Velho Bloomsbury, nos deparamos com a seguinte passagem: "No dia 16 de março [de 1905], Miss Power e Miss Malone jantaram conosco. Sydney-Turner e Gerald vieram após o jantar - a primeira das nossas noites de quinta" (WOOLF, 1920-1921: 128765). Se se trata de Eileen Power, não conseguimos confirmar.

8 "A sudden light upon the legs of Dame Elizabeth Partridge sends its beams over the whole state of England, to the King upon his throne; she wanted stockings! and no other need impresses you in quite the same way with the reality of mediaeval legs; and therefore with the reality of mediaeval bodies, and so, proceeding upward step by step, with the reality of mediaeval brains; and there you stand at the centre of all ages: middle begging or end" (WOOLF, 1906: posição 158160-158166).
} 
marginal, quanto o tipo de história que produz pode ser considerado com uma abordagem pouco convencional, ainda que em algum momento de sua carreira a historiadora tenha levado em consideração o tipo de documentação frequentemente estudado no período em questão ${ }^{9}$. Isto porque, com sua obra $O$ s registros da casa senhorial, Rosamond Merridew diz que não teria hesitado:

... em dedicar inúmeras páginas de letras grandes a uma tentativa de mostrar, de forma vívida, como em uma pintura, alguma cena da vida daquela época; aqui, bato na porta do servo, e o encontro assando coelhos que cozinhou; mostro o Senhor da mansão partindo para uma jornada, ou chamando seus cachorros para acompanhá-lo em uma caminhada pelo campo, ou sentado na cadeira de espaldar alto, inscrevendo laboriosas figuras sobre uma folha brilhante de pergaminho. Em outro quarto, mostro a você Dama Elinor, no trabalho com sua agulha; e a seus pés, em um banco mais baixo, senta sua filha também a costurar, mas menos assiduamente. 'Criança, o marido estará aqui antes que o linho da casa esteja pronto', reprova a mãe (WOOLF, 1906: 158174-158180).

Entretanto, tais reflexões sobre o passado não estiveram isentas de reprovações e críticas por parte dos interlocutores de Miss Merridew, que a ela lançaram dois tipos de contra-argumentos:

... primeiramente, eles dizem, tais digressões são muito boas para uma história da época, mas elas não tem nada que ver com o sistema de posse fundiária medieval; em segundo lugar, eles reclamam que eu não possuo materiais ao meu alcance para enriquecer estas palavras de algo que tenha qualquer semelhança com a verdade. É bem conhecido que o período que escolhi é mais infértil do que qualquer outro em registros privados; a menos que você decida retirar toda sua inspiração da Correspondência da Família Paston ${ }^{10}$ você deve

\footnotetext{
9 "What is notable about Merridew's research, therefore, is not that it is unorthodox, but quite the opposite: in terms of period and methodology her work is typical of historical studies at the beginning of the twentieth century" (KORE-SCHRÖDER, 2011: 3). Além do mais, a autora chama a atenção para o fato de que entre 1870 e 1930, principalmente com a fundação da London School of Economics em 1895, grande parte da produção de história social e econômica da Idade Média foi produzida por mulheres.

${ }^{10}$ As Paston Letters são consideradas a maior e talvez única coleção de correspondência privada do século $\mathrm{XV}$, contendo cerca de 1000 cartas e documentos que atestam o estado da terra, dispõem testamentos e listas de compras. Oferecem a possibilidade de investigação da vida de 3 gerações dessa família situada em Norfolk. Para mais informações: 〈https://blogs.bl.uk/digitisedmanuscripts/2015/04/the-paston-letters-golive.html>. Acesso em: 20 fev. 2019.
} 
se contentar em simplesmente imaginar, como qualquer outro contador de história ${ }^{11}$. E isso, me disseram, é uma arte útil em seu devido lugar; mas não se deveria ser permitido de clamar nenhuma relação com a severa arte do Historiador (WOOLF, 1906: 158180).

Em 1906, Virginia Stephen já colocava o dedo na ferida historiográfica ao problematizar as relações entre Literatura e História a partir do ponto de vista das fronteiras entre ficção e verdade ou verossimilhança, e sugerir um espaço de imaginação autorizada para a reconstituição de elementos de um passado que insistia em se esgueirar para fora de arquivos ou em se omitir daqueles pergaminhos amarelados que poucos podiam ou se interessavam em ler. Ao historiador preocupado em iluminar o passado tal qual ele fora, não seria permitido evocar o ausente, ou abrir com a palavra, pela narrativa, possibilidades de experiências vividas.

Finalmente, assim como nos ensaios memorialísticos de anos posteriores, temos neste conto que o ponto de partida para a investigação histórica, para a apresentação do passado, está dado no tempo presente. Unida à reprovação de ser ler a história em uma perspectiva teleológica, vista anteriormente, como se os homens do passado produzissem suas experiências tendo em mente leitores e investigadores futuros, tal quebra da linearidade narrativa pode indicar um posicionamento de Virginia de que a ordem do tempo não se dava de maneira progressiva, tal qual parece ter sido a norma da historiografia do século XIX (SPIROPOULOU, 2010). Afinal, não temos aqui a defesa de que o passado caminha de forma inexorável rumo ao progresso ou a um momento de realização futura. $\mathrm{O}$ que temos diante de nós é uma narrativa que se inicia pela apresentação de sua personagem em seu momento presente e tal conhecimento é fundamental, pois como Virginia Woolf atestaria em 1940, os fatos pouco significam se não sabemos a quem ocorreram. É, portanto, do presente que mergulhamos ao passado, ao mesmo tempo em que acompanhamos, in loco, a historiadora em seu cotidiano de pesquisa e investigação, a começar pela escolha e procura por sua fonte, no momento em que conseguiu deixar para trás a "velha discussão sobre o certo e errado, sobre a verdade e ficção em história" (WOOLF, 1906: 158186).

Com Rosamond Merridew partimos, então, em um dia de junho, rumo a Norfolk. Graças a seu olhar investigativo e quase arqueológico, nesta viagem, a historiadora se

\footnotetext{
${ }^{11}$ No inglês, story, o que ressalta a dicotomia que Virginia está elaborando entre Literatura e História e o útil papel que a imaginação tem para o contador de estórias, mas não para o historiador.
} 
depara com uma casa decadente, arruinada pelo passar do tempo, mas com ares de resguardar no interior de seus muros segredos de tempos passados. Naquela casa humilde, situada entre Norwich e East Harling, Miss Merridew imaginava residir uma família pobre e inconsciente de sua própria história, que não hesitaria nem por um segundo em vender a casa de seus ancestrais com seus manuscritos e objetos antigos. Enquanto se perdia nessas reflexões e pré-julgamentos, uma criada a recebeu e a conduziu à Senhora Martyn, a "pessoa de autoridade, a senhora da casa; aquela que tinha o direito de saber qual negócio me levava até ali” (WOOLF, 1906: 158209). Após uma breve incursão por quartos e cômodos destituídos de móveis e atrativos, Miss Merridew pôde comprovar o empobrecimento de seus habitantes em razão da desvalorização da terra, o que teria feito com que uma família importante e grandiosa em seu passado, agora dividisse seu espaço com o vazio, os ratos ou fantasmas de um passado grandioso. Convencida de que conseguiria uma boa barganha, Miss Merridew precisou, entretanto, aguardar o retorno de Senhor Martyn de seu cultivo diário da terra, para adensar o conhecimento sobre as possibilidades investigativas daquele lugar, já que ele era o homem que possuía a história no sangue e conhecia como ninguém o passado daquela propriedade e de sua genealogia.

Convidada para jantar e a permanecer na casa por mais algum tempo, Miss Merridew pôde ouvir as histórias da família, percorrer corredores que exibiam retratos da família Martyn em suas paredes, e adentrar no escritório que acolhia os registros de contabilidade, de pertences, de posses da terra, escritos pelos antepassados Martyn. Dentre tais documentos, estava o escrito de uma garota de cerca de 25 anos, letrada, que dedicara um ano de sua vida à escrita de um diário, onde narrava o dia-a-dia do funcionamento daquela mesma propriedade em 1480. E não só isso, foi somente ao entrar em contato com esses documentos e ouvir o que o descendente Martyn tinha a dizer sobre a história de sua terra e de seus ancestrais, que a historiadora pôde se dar conta do quão enganada estava sobre essas pessoas, orgulhosas de sua história, que valorizavam suas antiguidades, seus quadros nas paredes dispostos em ordem cronológica e os manuscritos que remontavam aos anos de 1480. Ao narrar a história de sua família à Miss Merridew, o Senhor Martyn intercalava a história pessoal com a nacional, como a de Willoughby Martyn que teria lutado em defesa da monarquia no momento anterior à Restauração e de Carlos I. O interesse pela história, ainda, relacionava-se, de maneira inequívoca, com o apego e dependência à terra e à casa que acolhera gerações através dos séculos. Os pergaminhos velhos e amarelados guardados no escritório serviram à comprovação e manutenção dos direitos de propriedade de Martyn, como também fora com a leitura do 
Diário de outra Senhora Martyn que o fazendeiro teria aprendido mais sobre sua terra. Desta forma, o passado era parte viva do presente, e percorria a carne e o sangue do próprio senhor da casa, em cuja mente:

Todas as gerações pareciam banhadas com a mesma clareza e luz: não era precisamente a luz do tempo presente, mas certamente não era aquilo que comumente chamamos de luz do passado. E não era romântico, era muito sóbrio, e muito amplo, e as figuras destacavam-se nela, sólidas e capazes, com uma grande semelhança, suspeito, com aquilo que eram na própria carne (WOOLF, 1906: 158333-158339).

Portanto, o Senhor Martyn não estava pronto para vender seus manuscritos antigos. Todavia, diante do interesse explícito de Miss Merridew em "histórias familiares, mesmo que não sejam a minha própria” (WOOLF, 1906: 158353), o anfitrião concedeulhe acesso aos documentos, a começar pelo Diário da Senhora Joana Martyn, pois, segundo afirmaria a historiadora, dever-se-ia começar pelo princípio. É então com certa dose de ironia que vemos sua própria imaginação se provar equivocada quando dirigida aos seus contemporâneos e considerá-los ignorantes, desapegados em relação ao seu passado e mergulhados em tamanha pobreza que os impulsionaria a vender cada parte destes séculos. Não é por acaso que a historiadora se reconheça abismada ao ouvir de seu anfitrião a notícia de que não venderia aqueles manuscritos nem por $£ 20$, pois não saberia como viver sem seus familiares por perto já que "eles são, ele teria me dito, carne e sangue como eu [...]" (WOOLF, 1906: 158342-158348).

A segunda parte deste conto foi, portanto, dedicada à exposição do Diário da Senhora Joana Martyn e da mesma forma que na primeira parte do texto, encontramos uma escrita em primeira pessoa. Não sabemos se já temos diante dos olhos a edição organizada pela historiadora, se estamos lendo em primeira mão o manuscrito original, ou se ao deixar que a documentação fale por si, descobrimos parte da metodologia de Miss Merridew para conferir legitimidade ao seu mergulho ao passado; metodologia esta que poderíamos considerar tradicional por deixar que o passado falasse por si mesmo, sem intervenções do historiador, e meio na contramão do que a própria Miss Merridew havia atestado previamente, quando defendeu a importância da imaginação para a reconstrução de passados remotos contra seus críticos. Saboreando mais uma ironia de Virginia, descobrimos que não voltaremos a encontrar Miss Merridew nesta história, e 
que a historiadora não terá um papel de alinhavadora das linhas do tempo. Somos deixamos com os pensamentos de Joana Martyn, escritos também em forma de diário, possivelmente, conforme falamos, em 1480. Em primeiro lugar, novamente nos deparamos com uma escolha corajosa. Não só nossa historiadora é uma mulher de destaque em sua época e ofício, como seu objeto de estudo é uma mulher extraordinária para sua época, já que sabe ler, escrever e apreciar a arte da escrita. Em um momento em que a historiografia voltava ainda sua atenção para os grandes homens e acontecimentos do passado, analisados por meio de registros oficiais de contabilidade e legislação, neste conto, Rosamond Merridew nos abre as portas para o conhecimento do cotidiano da administração de um senhorio, a partir da leitura de um texto que registra os pensamentos diários de uma garota. E, novamente aqui, temos a concentração no tempo presente, já que o diário é composto por várias anotações feitas em momentos precisos. Ainda quando narrado, o passado é visto e organizado como um tempo presente para aqueles que o vivenciam. Não é somente o passado que se esgueira por entre as frestas do presente, mas é o presente que está posto no passado em sua passagem regular de dias, de meses, e na demarcação das estações do ano. Não por acaso, ouvimos da boca de Joana Martyn que:

Da minha janela, aprecio o jardim da igreja, onde tantos dos meus ancestrais estão enterrados, e na minha oração eu tenho piedade por todos os pobres mortos que se lançam perpetuamente nas frias águas correntes; pois eu os vejo circulando e remoinhando para sempre em uma pálida onda. Deixe-nos, então, os que tem o dom do presente, usá-lo e aproveitá-lo (WOOLF, 1906: 158412).

Ademais, assim como ocorreu na primeira parte do conto, o escrito tem início com a apresentação dos personagens, dos sujeitos que vivenciam os acontecimentos. Joana Martyn aborda sua época, repleta de inseguranças; fala de seu espaço, que garante segurança e proteção; e descreve os integrantes do senhorio, a começar pela mãe, a dirigente da casa, que governa a terra e a todos, atenta em resguardar os direitos da família, quando os homens estão ausentes em incursões a Londres ou no exército. $\mathrm{O}$ senhorio é ainda composto pelo padre Sir João Sandys, servo fiel da mãe de Joana e responsável por ministrar os ofícios sagrados. Conhecemos também os servos domésticos Guilherme e Anne, cujas memórias resguardam lembranças passadas que se confundem com a própria existência da propriedade. E, finalmente, o irmão mais novo de Joana, Jeremias. Vemos essa família estendida reunida em torno do fogo, em um dia de inverno, 
naquela mesma sala de estar em que a Senhora Martyn costurava quando fora interrompida pela chegada de uma visitante não esperada. Todavia, esta outra Senhora Martyn, que habitava essas paredes em 1480, não se ocupava da costura, mas era a responsável por ler em voz alta, para entreter os membros da casa, histórias de tempos passados, como o manuscrito do Palácio de vidro de John Lydgate, um poema que tratava sobre a guerra de Tróia e sobre os dissabores e aventuras de outra mulher, Helena. Mas também vemos a mãe de Joana sentada à mesa, naquele mesmo escritório que, séculos mais tarde, ainda guardaria os documentos escritos por Joana e outros antepassados como o registro da contabilidade do senhorio, que a mãe tem diante de si e o Senhor Martyn apresentaria como prova fundamental na comprovação de seus direitos de propriedade diante da corte.

Outros instantes precisos são relatados no diário, como a chegada do trovador Ricardo, em um dia de primavera, evento que reuniu a família, os agregados e os servos em torno da narrativa de histórias ocorridas na longínqua Cornualha, na corte do rei Arthur e sua Távola Redonda, sobre um de seus cavalheiros mais respeitados, Tristão, e sua rainha Isolda. Este artista, andarilho, que percorria terras diversas vendendo livros e contando histórias em troca de comida e pouso, encanta os olhos e ouvidos de Joana com seus manuscritos iluminados em letras bem adornadas e cuidadosamente dispostas sobre o pergaminho. Mas nem todos os homens que perambulam são atraentes ou merecem o respeito e os ouvidos dos membros da família Martyn. Joana relata como a posse ou o pertencimento a uma terra garante a identidade de um homem ou mulher, e como aqueles que dela estão destituídos vivem à margem da legalidade e da própria condição de humanidade. Em dois episódios temos essa aproximação entre o homem e o animalesco; entre o andarilho que assombra por seu desterramento e o servo pela sua a condição de vida miserável, em um chalé que abriga a família de servos Beatriz e Pedro Sommes. Finalmente, também entramos em contato com o mundo externo, com a movimentação dos homens por dentre estradas que escondem outros perigos, quando um dos emissários da família empreende uma viagem a Londres para entregar uma correspondência ao pai de Joana, ausente de sua terra por conta da guerra e das disputas que grassavam a Inglaterra no século XV.

Desta forma, todos os personagens de uma sociedade medieval ganham vida por meio de uma narrativa literária e estão expostos diante de nós no instante em que existem em uma vida de insegurança e perigo interno e externo que rodeia aqueles que pertencem e dominam terras e homens. Com este conto, acreditamos que Virginia não tenha tido 
intenção de compor um romance histórico, já que desde suas primeiras linhas nos informa sobre a importância da imaginação para a composição da sua trama e da reconstituição do passado. Todavia, tampouco podemos considerar que sua escrita seja um ato puro de imaginação, sem ancoragens no presente da autora e do passado da Inglaterra, dado o conhecimento que demonstrou ter dos debates que circulavam no período e dos rumos das pesquisas historiográficas realizadas no momento, talvez, principalmente, pela proximidade e amizade que mantinha com Frederic William Maitland. A importância dessa relação e do impacto que o medievalista desempenhou na reflexão de Woolf sobre a história parece ter sido vital, a ponto de Leena Kore-Shröder (2011) considerar que com este conto Virginia tinha por finalidade prestar uma homenagem ao historiador, que morreria antes de ver o texto publicado. Razão pela qual, argumenta a estudiosa, o conto teria ficado por muitos anos sem publicação. Ainda assim, não podemos deixar de reconhecer a ousadia da jovem escritora ao formular ou imaginar uma história escrita a partir de uma documentação não convencional, que demonstra a existência de um sujeito no ato de registro da sua própria vida, como ela própria faria em 1940, nos meses que antecederam sua morte.

\section{Linhas finais}

A história escrita do ponto de vista feminino em seu duplo sentido de sujeito e objeto também não deixa de surpreender, assim como o enfoque escolhido por Virginia pela exposição da vida social, doméstica e familiar. Com o Diário da Senhora Joana Martyn, estamos bem longe de uma história que tem como principal tarefa o registrar e recordar acontecimentos grandiosos como a guerra, as disputas políticas e territoriais, movidos por grandes homens. Assim como Woolf não deixou de se preocupar com a importância do registro de uma vida, no presente, também não deixou de alertar para as diferenças e desequilíbrios entre os gêneros, constituindo seus ensaios Um teto todo seu (1929) e Três guinéus (1938), escritos nos quais aprofundou e detalhou seus argumentos. Virginia Woolf incansavelmente alertou para a diferença de condições de educação e oportunidades garantidas aos homens e mulheres, e usou sua voz para chamar a atenção para uma história da Literatura feita, estudada, registrada e dominada por homens, na qual uma imaginada irmã de Shakespeare não poderia produzir arte, sobretudo por lhe faltar as condições materiais essenciais a toda produção intelectual (WOOLF, 1929). Seria 
necessário um teto, um cômodo privado, e renda para que se pudesse escrever. Talvez não por outra razão que ao procurar pelas mulheres na história e na ficção, Virginia Woolf teria se deparado com estantes vazias e livros inexistentes:

O que alguém precisaria fazer para trazer a mulher à vida era pensar de forma poética e prosaica ao mesmo tempo, mantendo-se assim em contato com a realidade - que ela é a senhora Martin, tem trinta e seis anos, está vestida de azul, usa chapéu preto e sapatos marrons. Mas sem perder de vista a ficção que ela é o receptáculo para o qual todo tipo de espíritos e forças ruma e pelo qual passa rápida e perpetuamente. No momento, porém, em que alguém experimenta esse método com a mulher elisabetana, uma parte da iluminação se perde; a pessoa se depara com a escassez dos fatos. Não se sabe nenhum detalhe, nada realmente verdadeiro e sólido. A história sequer a menciona. E recorro ao professor Trevelyan mais uma vez para entender o que a história significa para ele. Descubro, ao olhar para o nome dos capítulos, que significa 'A corte feudal e os métodos de agricultura em campo aberto ... As cistercienses e a criação de ovelhas ... As Cruzadas... A universidade... A Câmara dos Comuns ... A Guerra dos Cem Anos... A Guerra das Rosas... Os intelectuais do Renascimento... A dissolução dos mosteiros... Disputa agrária e religiosa... A origem do poder marítimo inglês... A Armada...', e assim por diante. [...] a vida da mulher elisabetana comum deve estar espalhada por aí, em algum lugar, para ser recolhida e transformada em livro. Seria uma ambição à qual não me atrevo, pensei, ao procurar nas prateleiras por livros que não estavam lá, sugerir para os alunos daquelas universidades famosas que reescrevessem a história, ainda que, para mim, com frequência ela pareça estranha como é, irreal, desequilibrada; mas por que eles não poderiam acrescentar um suplemento à história, dando a ele, lógico, um nome imperceptível, de modo que as mulheres pudessem nele figurar sem impropriedades? (WOOLF, 1929: 67-68).

Ao longo deste artigo, insistimos no modernismo de Woolf. Mas talvez, tal modernidade e o frescor de seu pensamento estejam naquilo que ainda não tenhamos dito. Ou feito. Consideramos Virginia uma escritora moderna pelo caráter de sua escrita desafiadora, pelo grupo do qual fez parte que insistia na importância da originalidade e de se ter consciência de que se vivia em tempos modernos; pelos escândalos e polêmicas 
nos quais se envolveu. Mas foi somente ao atentar para a relação que estabeleceu entre História e Literatura e como reelaborou a passagem e a direção do tempo que fomos capazes de perceber o quanto a nossa historiografia e a forma como nos relacionamos com a temporalidade em História ainda é tributária de uma historiografia de finais do século XIX e início do XX. Por mais que o século XX tenha sido rico em tentativas de inovações dos métodos, objetos e abordagens à disposição do historiador, parece que há ainda um longo caminho a ser percorrido no reconhecimento do lugar das mulheres na história e na historiografia.

Ademais, se, conforme nos disse Woolf, a Guerra teria desempenhado um papel decisivo na percepção que seus contemporâneos tinham sobre seu passado, fazendo com que os escritores exaltassem mais as diferenças e as fissuras incontornáveis do que as semelhanças entre sua era e a de seus antepassados, a própria composição de Virginia parece sugerir que o passado está no aqui, assim como o passado um dia foi agora, um instante. Ou seja, sua estética e o olhar que lançou sobre seu tempo presente, de fato, estão vinculados à modernidade no que há de ênfase no novo, no fragmentário, na invenção de gêneros que contenham, sem limitar, a escrita. Mas em seus escritos, também existe uma insistência na inevitável proximidade entre passado e presente, que não se dá por via de causalidade ou de uma linearidade progressiva, mas por imersão e reinvenção. No conto que expusemos, isto aparece quando, por exemplo, os tempos são entrecruzados e sobrepostos na casa, no edifício material que é palco da vivência dos Martyn, contendo os mesmos cômodos, funções e escritos. Também, na forma como os documentos escritos no século XIV e XV, são citados em seu momento de elaboração, e de constantes leituras e retomadas ao longo dos séculos. Temos o mesmo registro de contabilidade ser lido pela mãe de Joana Martyn, pelo Senhor Martyn, por Rosamond Merridew, e porque não dizer, por Maitland e as historiadoras do London School of Economics. Entretanto, não se trata de um tempo vivido na sua progressão, já que somos alertados para o empobrecimento das condições de vida dos Martyn. Também, não parece possível dizer que se trata de um tempo circular ou que se reproduz e retorna eternamente (WILLIAMS, 2002). O passado está aqui, no agora, na materialidade das ruínas, no amarelamento de páginas, no abandono que exala do empobrecimento, mas que permanece em carne e sangue, como uma fotografia que se mantém viva por detrás do vidro que a protege, mas que já perdeu parte de seu vigor. O passado permanece imaterialmente como memória, como lembrança, em outro "dia em junho” no qual Mrs Dalloway (1924) sai para escolher as flores que adornariam a festa que daria aos grandes de seu tempo, enquanto é 
acompanhada em sua caminhada pelas badaladas do Big Ben que recorda a todos sobre a passagem inexorável do tempo. Ao nos questionarmos sobre a relação entre História e Literatura e sobre a temporalidade em Woolf, portanto, não deixamos de pensar no poema escrito em cerca de 1861, por Charles Baudelaire, o inaugurador da modernidade, que atestava a transitoriedade da vida e da importância de se flainar pelo presente. E de se recordar:

O relógio! Um deus sinistro e impassível

Cujos dedos ameaçadores nos diz: 'Recorda!

Logo em seu coração angustiado, como em um alvo,

Estremecidos poços de Sofrimento irão se instalar;

Prazer Vaporoso desliza para o horizonte

Tal qual um silfo esvoaça as asas;

Cada instante devora um pedaço da delícia

Que a um homem é concedida por sua estadia terrena.

Três mil e seiscentas vezes por hora

O Segundo suspira, Recorda! - Repentinamente

O Agora, com voz de inseto, diz: Eu sou Outrora

E suguei sua vida com minhas narinas imundas!

Esto memor! Remember! Souviens-toi!

(Minha garganta de metal fala em todas as línguas)

Não deixe os minutos, prodigiosos, serem desperdiçados -

Eles são o minério do qual você deve extrair o ouro!

Remember, o Tempo é ganancioso no jogo

E ele ganha todas as jogadas! é a lei.

O dia se esvai; anoitece, recorde!

O abismo está sempre sedento; a clepsidra se esvazia.

Logo soa a hora em que o celestial Acaso,

Em que a augusta Virtude, sua esposa ainda virgem,

Mesmo em que (oh! seu último refúgio) o Arrependimento,

Te dirão: Morra velho covarde! Já é tarde! (BAUDELAIRE, 1861) 


\section{Fontes}

WOOLF, Virginia (1906). "Journal of Mistress Joan Martyn". The Complete shorter fiction. In: Virginia Woolf: the complete collection. Golden Deer Classics. Versão kindle.

(1905). "The Letters". In: Virginia Woolf: the complete collection. Golden Deer Classics. Versão kindle.

(1920-1921) "Old Bloomsbury" (1920-1921). Moments of Being. In: Virginia Woolf: the complete collection. Golden Deer Classics. Versão kindle.

(1923). "How it strikes a contemporary". In: WOOLF, Virginia. Selected essays. Oxford University Press, 2009.

(1939-1941). "A sketch of the past". Moments of Being. In: Virginia Woolf: the complete collection. Golden Deer Classics. Versão kindle.

(1940). "The diary". In: Virginia Woolf: the complete collection. Golden Deer Classics. Versão kindle.

(1980[1924]). Mrs Dalloway (1924). Editora Nova Fronteira.

(2003[1927]). Rumo ao farol. O Globo.

(2014[1929]). Um teto todo seu. Tordesilhas.

\section{Referências Bibliográficas}

BAUDELAIRE (2008). The flowers of evil. Oxford University Press.

BELL, Quentin (1972). Virginia Woolf. A biography. The Hogarth Press, vol. I.

LEE, Hermione (2008). Body Parts: essays on life-writing. Pimlico. (1999). Virginia Woolf. Vintage.

Leena Kore-Schröder (2008). "Who is afraid of Rosamond Merridew?: Reading medieval history in 'The journal of Mistress Joan Martyn'. Journal of the short story in English, 50, pp. 01-13.

MALCOLM, Janet. Uma casa toda sua. In: 41 inícios falsos. São Paulo: Companhia das Letras, 2010.

McAVOY, Siriol (2016). The presence of the past: medieval encounters in the writing of Virginia Woolf and Lynette Roberts. Cardiff University/School of English, Communication and Philosophy of Cardiff. Tese (Doutorado).

NEVES, Caroline Resende (2018). Virginia Woolf e o espaço autobiográfico em Os Anos. Universidade Federal de Juiz de Fora. Dissertação (Mestrado).

SPALDING, Frances (2016). Vanessa Bell. Portrait of the Bloomsbury artist. Taurus Parke Paperbacks.

SPIROULOU, Angeliki (2010). Virginia Woolf, modernity and history: constellations with Walter Benjamin. Palgrave Macmillan.

WILLIAMS, Louise Blakeney (2002). Modernism and the ideology of History. Literature, politic and the past. Cambridge University Press.

WILLIAMS, Raymond (2011). "O círculo de Bloomsbury". In: Cultura e materialismo. Editora UNESP. 
Artigo recebido em 30 de abril de 2019.

Aprovado em 20 de maio de 2019.

DOI: 10.12957/intellectus.2019.36854 